\title{
Patient-Reported Ocular Disorders and Symptoms in Adults with Moderate-to-Severe Atopic Dermatitis: Screening and Baseline Survey Data from a Clinical Trial
}

Jonathan Weyne - Andrew Blauvelt - Marjolein de Bruin-Weller •

Errol Prens · Penny Asbell · Debra Sierka · Zhen Chen •

Brad Shumel

Received: August 5, 2020 / Published online: October 12, 2020

(C) The Author(s)

\section{ABSTRACT}

Introduction: Patients with atopic dermatitis (AD) have a greater risk of conjunctivitis and other ocular surface disorders than the general population. We evaluated the burden of ocular surface disorders and related symptoms prior to treatment initiation in adults with moderate-tosevere AD.

Methods: Patients were enrolled in a randomized, placebo-controlled, double-blinded, phase 3 trial of dupilumab administered with concomitant topical corticosteroids. At the

J. Weyne $(\varangle) \cdot$ Z. Chen · B. Shumel

Regeneron Pharmaceuticals, Inc., 777 Old Saw Mill

River Road, Tarrytown, NY 10591-6707, USA

e-mail: jonathan.weyne@regeneron.com

A. Blauvelt

Oregon Medical Research Center, Portland, OR, USA

M. de Bruin-Weller

National Expertise Center of Atopic Dermatitis,

Department of Dermatology and Allergology,

University Medical Center, Utrecht, Netherlands

E. Prens

Erasmus University Medical Center, Rotterdam,

Netherlands

P. Asbell

Hamilton Eye Institute, University of Tennessee

Health Science Center, Memphis, TN, USA

D. Sierka

Sanofi Genzyme, Cambridge, MA, USA beginning of the screening period, all enrolled patients completed a survey of ocular disorder diagnoses received in the past year; at baseline, patients completed a survey of frequency and severity of ocular symptoms (discomfort, itching, redness, and tearing) experienced in the past month.

Results: A total of 712 of 740 patients enrolled in the trial provided responses to the survey. At screening, 286 of 740 patients (38.6\%) reported having at least one ocular disorder in the past year. At baseline, 499 of 712 respondents (70.1\%) reported having at least one symptom within the past month. Of these patients, $4.4 \%$, $6.0 \%, 5.5 \%$, and $4.4 \%$, respectively, reported having discomfort, itching, redness, and tearing all of the time. Mild discomfort, itching, redness, and tearing were reported by $26.1 \%$, $33.7 \%, 30.8 \%$, and $31.6 \%$ of patients, respectively, while $7.3 \%, 7.7 \%, 6.2 \%$, and $4.2 \%$, reported severe discomfort, itching, redness, and tearing, respectively.

Conclusions: These data demonstrate a high burden of ocular surface disorders and related symptoms in a population of adults with moderate-to-severe AD. Dermatologists should be aware of increased incidence of these disorders in $\mathrm{AD}$ and query their patients for signs and symptoms of eye disease.

ClinicalTrials.gov Registration Number: NCTO 2260986. 
Keywords: Atopic dermatitis; Burden; Ocular disorders; Symptoms; Survey

\section{Key Summary Points}

Why carry out this study?

Patients with atopic dermatitis (AD) have a greater risk of conjunctivitis and other ocular surface disorders than the general population.

We evaluated the burden of ocular surface disorders and related symptoms prior to treatment initiation with dupilumab in adults with moderate-to-severe $\mathrm{AD}$ enrolled in a randomized, placebocontrolled, double-blinded phase 3 trial of dupilumab administered with concomitant topical corticosteroids.

\section{What was learned from the study?}

These data demonstrate a high burden of ocular surface disorders and related symptoms in a population of adults with moderate-to-severe AD.

Dermatologists should be aware of increased incidence of these disorders in $\mathrm{AD}$ and query their patients for signs and symptoms of eye disease.

\section{DIGITAL FEATURES}

This article is published with digital features to facilitate understanding of the article. You can access the digital features on the article's associated Figshare page. To view digital features for this article go to https://doi.org/10.6084/m9. figshare.12998804.

\section{INTRODUCTION}

Patients with atopic dermatitis (AD) have a greater risk of conjunctivitis and other ocular surface disorders (e.g., atopic keratoconjunctivitis [AKC], keratoconus, herpetic eye disease, and dry eye) than the general population [1-12]. The prevalence rates of ocular surface disorders in patients with $\mathrm{AD}$ are high, with studies showing up to $32-42 \%$ of patients with $\mathrm{AD}$ reporting eye disease or prescriptions for eye disorders in the past 12 months $[1,5,6]$. Some of these disorders, such as AKC, may lead to serious eye problems, impaired vision, or even vision loss [3, 4, 9]. Incidence of ocular surface disorders increases with $\mathrm{AD}$ severity and factors related to $\mathrm{AD}$ severity, including elevated circulating levels of IgE, thymus and activation-regulated chemokine, and eosinophils $[1,6,13]$.

To provide further information on the prevalence and severity of these disorders, particularly in patients with moderate-to-severe $\mathrm{AD}$, we evaluated the burden of ocular surface disorders and related symptoms prior to treatment initiation in adults with moderate-tosevere $\mathrm{AD}$ enrolled in a phase 3 trial of dupilumab.

\section{METHODS}

LIBERTY AD CHRONOS (NCT02260986) was a randomized, placebo-controlled, double-blinded, phase 3 trial of dupilumab administered with concomitant topical corticosteroids [14]. Detailed patient eligibility criteria were previously published [14]. In brief, patients were eligible to enroll in CHRONOS if they were at least 18 years of age, and had chronic moderateto-severe $\mathrm{AD}$, inadequate response to mediumto high-potency topical corticosteroids (with or without concomitant topical calcineurin inhibitors) within 6 months before screening, an Investigator's Global Assessment Score of at least 3 (on a scale of $0-4$, where 3 was moderate and 4 was severe), and an Eczema Area and Severity Index score of at least 16 at screening and baseline.

At the beginning of the 35-day screening period, patients completed a survey of ocular disorder diagnoses received in the past year. At baseline, they completed a survey of frequency and severity of ocular symptoms (itching, 
Table 1 Screening: ocular surface disorders during the past year

\begin{tabular}{lllll}
\hline Screening question & Yes & No & I don't know & Missing \\
\hline Responded to survey, $n / N(\%)$ & $712 / 740(96.2)$ & $28 / 740(3.8)$ & - & - \\
Reported $\geq 1$ eye disorder in the past year & $286 / 740(38.6)$ & - & - & - \\
Do you have or have you had, $n I(\%)^{\mathrm{a}}$ & & & \\
AKC & $87(12.2)$ & $523(73.5)$ & $101(14.2)$ & $1(0.1)$ \\
Dry eye & $146(20.5)$ & $533(74.9)$ & $33(4.6)$ & 0 \\
HSV of the eye & $30(4.2)$ & $650(91.3)$ & $32(4.5)$ & 0 \\
Keratoconus & $15(2.1)$ & $609(85.5)$ & $87(12.2)$ & $1(0.1)$ \\
Perennial allergic conjunctivitis & $107(15.0)$ & $524(73.6)$ & $81(11.4)$ & 0 \\
Rosacea of the eye & $19(2.7)$ & $650(91.3)$ & $43(6.0)$ & 0 \\
\hline
\end{tabular}

$A K C$ atopic keratoconjunctivitis, $H S V$ herpes simplex virus infection, $N$ number of patients enrolled in the study, $n$ number of patients who responded to the survey, $n l$ number of patients with given response

a The percentage is the number of patients with a given response divided by the total number of patients who responded to the survey; patients may have had more than one ocular disorder diagnosed in the past year

tearing, redness, and discomfort) experienced in the past month.

The number and proportion of patients at screening who reported ocular disorder diagnoses in the past year, and the number and proportion of patients at baseline reporting frequency and severity of symptoms, were analyzed using descriptive statistics, based on the number of patients who provided responses to the survey.

The study was conducted in accordance with the provisions of the Declaration of Helsinki, the International Conference on Harmonisation Good Clinical Practice guideline, and applicable regulatory requirements. The protocol was reviewed and approved by institutional review boards/ethics committees at all study sites. An independent data monitoring committee monitored patient safety. All patients provided signed written informed consent.

\section{RESULTS}

Of the 740 patients enrolled in CHRONOS, 712 provided responses to the survey. At screening,
286 of 740 patients $(38.6 \%)$ reported having at least one ocular disorder in the past year. Among the 712 respondents to the survey, the most common ocular disorder reported in the past year was dry eye (20.5\% of patients), while the least common disorder reported was keratoconus $(2.1 \%$ of patients) (Table 1$)$. Eightyseven patients (12.2\%) reported AKC, a potentially serious ocular disorder, in the past year (Table 1).

Of the 712 respondents to the survey, 499 patients (70.1\%; comprising $67.4 \%$ of all enrolled patients) reported having at least one symptom within the past month at baseline. A total of $47.9 \%, 65.0 \%, 53.8 \%$, and $49.9 \%$ of survey respondents, respectively, reported symptoms of discomfort, itching, redness, and tearing in the past month (Table 2). Of these patients, few reported having symptoms all of the time (4.4\% [discomfort], 6.0\% [itching], $5.5 \%$ [redness], and $4.4 \%$ [tearing]) (Table 2). Mild symptoms of discomfort, itching, redness, and tearing were reported by $26.1 \%, 33.7 \%$, $30.8 \%$, and $31.6 \%$ of patients, respectively (Table 2). Fewer patients (15.0\%, 22.6\%, 15.3\%, and $12.5 \%$, respectively) reported moderate 
Table 2 Baseline: frequency and severity of ocular symptoms during the past month

\begin{tabular}{lcccc}
\hline Baseline question, $\boldsymbol{n ( \% ) ^ { \mathbf { a } }}$ & $\begin{array}{l}\text { Discomfort } \\
\boldsymbol{N}=\mathbf{7 1 2}\end{array}$ & $\begin{array}{l}\text { Itching } \\
\boldsymbol{N}=\mathbf{7 1 2}\end{array}$ & $\begin{array}{l}\text { Redness } \\
\boldsymbol{N}=\mathbf{7 1 2}\end{array}$ & $\begin{array}{l}\text { Tearing } \\
\boldsymbol{N}=\mathbf{7 1 2}\end{array}$ \\
\hline $\begin{array}{l}\text { Frequency of symptom } \\
\text { None of the time }\end{array}$ & $371(52.1)$ & $249(35.0)$ & $329(46.2)$ & $357(50.1)$ \\
Some of the time & $186(26.1)$ & $248(34.8)$ & $216(30.3)$ & $219(30.8)$ \\
Half of the time & $61(8.6)$ & $80(11.2)$ & $57(8.0)$ & $55(7.7)$ \\
Most of the time & $63(8.8)$ & $92(12.9)$ & $71(10.0)$ & $50(7.0)$ \\
All of the time & $31(4.4)$ & $43(6.0)$ & $39(5.5)$ & $31(4.4)$ \\
Any of the time & $341(47.9)$ & $463(65.0)$ & $383(53.8)$ & $355(49.9)$ \\
Severity of symptom & & & & $360(51.7)$ \\
None & $367(51.5)$ & $256(36.0)$ & $219(30.8)$ & $225(31.6)$ \\
Mild & $186(26.1)$ & $240(33.7)$ & $109(15.3)$ & $89(12.5)$ \\
Moderate & $107(15.0)$ & $161(22.6)$ & $44(6.2)$ & $30(4.2)$ \\
Severe & $52(7.3)$ & $55(7.7)$ &
\end{tabular}

$N$ number of patients who responded to the survey

a The percentage is the number of patients with a given response divided by the total number of patients who responded to the survey; patients may have had more than one symptom in the past month

b Any of the time comprises some, half, most, or all of the time for a particular symptom; patients may have had more than one symptom at the same time

symptoms of discomfort, itching, redness, and tearing; and only $7.3 \%, 7.7 \%, 6.2 \%$, and $4.2 \%$, respectively, reported severe symptoms (Table 2).

\section{DISCUSSION}

This survey demonstrated a substantial burden of ocular surface disorders within the past year in patients with moderate-to-severe $\mathrm{AD}$ that was inadequately controlled with topical medications. Most patients reported having at least one ocular symptom within the past month at baseline, and a substantial proportion of symptoms were moderate to severe. The burden of ocular surface disorders in this patient population is consistent with other studies demonstrating a substantially greater incidence of ocular surface disorders among patients with type 2 inflammatory disorders, such as AD, asthma, and rhinosinusitis, compared with the general population [1-12].
Previous studies have demonstrated an association of AD severity with increased risk of ocular disorders $[1,6,13]$. Although the burden of ocular disorders has been demonstrated to be high in patients with $\mathrm{AD}$ compared with the general population [1-12], there is also an association of $\mathrm{AD}$ with other type 2 inflammatory comorbidities such as allergies, asthma, and rhinitis, and in turn these type 2 inflammatory diseases are also associated with increased incidence of ocular disorders $[15,16]$. Therefore, it is difficult to identify the relative contributions of $\mathrm{AD}$ and other associated type 2 inflammatory disorders to comorbid ocular diseases.

Some ocular disorders associated with $\mathrm{AD}$, such as $\mathrm{AKC}$, are potentially serious and may have an impact on vision, and, therefore, require ophthalmic assessment and treatment $[1,3,4,9]$. Given the demonstrated association of ocular diseases with $\mathrm{AD}$, it is important to increase awareness of the burden, signs and 
symptoms, and management guidelines for ocular disease associated with $\mathrm{AD}$ among dermatologists [17, 18].

Limitations of this survey include a population comprised of patients who were screened and enrolled in a clinical trial, which may not be representative of all patients with moderateto-severe $\mathrm{AD}$; however, this is a limitation of all randomized clinical trials. The survey is a nonvalidated instrument, and it is possible that some patients may not have understood the medical terms of the questionnaire. Survey data for diagnoses are subject to recall bias; symptom data may be more reliable, as they reflect patient experience within the previous month.

\section{CONCLUSION}

These data demonstrate a high burden of ocular surface disorders and related symptoms in a population of adults with moderate-to-severe AD. Dermatologists should be aware of increased incidence of these disorders in patients with $\mathrm{AD}$ and query their patients for signs and symptoms of eye disease.

\section{ACKNOWLEDGEMENTS}

The authors thank the patients and their families for their participation in this study; their colleagues for their support; and Linda Williams (Regeneron Pharmaceuticals, Inc.), and Adriana Mello and El-Bdaoui Haddad (Sanofi Genzyme) for their contributions.

Funding. Research sponsored by Sanofi and Regeneron Pharmaceuticals, Inc. ClinicalTrials.gov Identifier NCT02260986. The study sponsors have funded the Journal's Rapid Service fee for this paper.

Medical Writing and Editorial Assistance. Medical writing/editorial assistance provided by Vicki Schwartz, PhD, of Excerpta Medica, funded by Sanofi Genzyme and Regeneron Pharmaceuticals, Inc.
Prior Presentation. Content included in this manuscript was previously accepted for a poster presentation at the Society for Investigative Dermatology (SID) 2020 Annual Meeting; May 13-16, 2020. However, the meeting was held virtually, and no posters were presented. The abstract was published in the SID 2020 Meeting Abstract Supplement of the Journal of Investigative Dermatology (J Invest Dermatol. 2020;140[7Suppl]:S53 [Abstract 407]).

Disclosures. Jonathan Weyne, Zhen Chen, Brad Shumel are employees and shareholders of Regeneron Pharmaceuticals, Inc. Andrew Blauvelt is a scientific adviser, clinical study investigator for AbbVie, Aclaris, Almirall, Arena, Athenex, Boehringer Ingelheim, Bristol Myers Squibb, Dermavant, Dermira, Eli Lilly, Forte, Galderma, Janssen, LEO Pharma, Novartis, Ortho Derm, Pfizer, Rapt, Regeneron Pharmaceuticals, Inc., Sandoz, Sanofi Genzyme, Sun Pharma, UCB; and a paid speaker for AbbVie. Marjolein de Bruin-Weller is a Principal Investigator, advisory board member, consultant for Regeneron Pharmaceuticals, Inc., Sanofi Genzyme; Principal Investigator, advisory board member for AbbVie, Pfizer; and an advisory board member for Eli Lilly, and UCB. Errol Prens has received honoraria and/or research grants from AbbVie, Amgen, Celgene, Eli Lilly, Galderma, Janssen-Cilag, Novartis, Pfizer, Regeneron Pharmaceuticals Inc., Sandoz, Sanofi Genzyme, and UCB. Penny Asbell is an advisory board member and consultant for Regeneron Pharmaceuticals, Inc. Debra Sierka is an employee, and may hold stock and/or stock options in Sanofi Genzyme.

Compliance with Ethics Guidelines. The study was conducted in accordance with the provisions of the Declaration of Helsinki, the International Conference on Harmonisation Good Clinical Practice guideline, and applicable regulatory requirements. The protocol was reviewed and approved by institutional review boards/ethics committees at all study sites. An independent data monitoring committee monitored patient safety. All patients provided signed written informed consent. 
Author Contributions. All authors meet the International Committee of Medical Journal Editors (ICMJE) criteria for authorship for this article, take responsibility for the integrity of the work as a whole, and have given their approval for this version to be published.

Data Availability. Qualified researchers may request access to study documents (including the clinical study report, study protocol with any amendments, blank case report form, statistical analysis plan) that support the methods and findings reported in this manuscript. Individual anonymized participant data will be considered for sharing once the product and indication has been approved by major health authorities (e.g., FDA, EMA, PMDA, etc), if there is legal authority to share the data and there is not a reasonable likelihood of participant re-identification. Submit requests to https://vivli.org/.

Open Access. This article is licensed under a Creative Commons Attribution-NonCommercial 4.0 International License, which permits any non-commercial use, sharing, adaptation, distribution and reproduction in any medium or format, as long as you give appropriate credit to the original author(s) and the source, provide a link to the Creative Commons license, and indicate if changes were made. The images or other third party material in this article are included in the article's Creative Commons license, unless indicated otherwise in a credit line to the material. If material is not included in the article's Creative Commons license and your intended use is not permitted by statutory regulation or exceeds the permitted use, you will need to obtain permission directly from the copyright holder. To view a copy of this license, visit http://creative commons.org/licenses/by-nc/4.0/.

\section{REFERENCES}

1. Thyssen JP, Toft PB, Halling-Overgaard A-S, Gislason GH, Skov L, Egeberg A. Incidence, prevalence, and risk of selected ocular disease in adults with atopic dermatitis. J Am Acad Dermatol. 2017;77: 280-6.

2. US Department of Health and Human Services Public Health Service, National Center for Health Statistics. Eye conditions and related need for medical care among persons 1-74 years of age: United States, 1971-72. DHHS Publication No. (PHS) 83-1678. 1983. https://www.cdc.gov/nchs/ data/series/sr_11/sr11_228.pdf. Accessed 11 Feb 2020.

3. Beck KM, Seitzman GD, Yang EJ, Sanchez IM, Liao W. Ocular co-morbidities of atopic dermatitis. Part 1: associated ocular diseases. Am J Clin Dermatol. 2019;20:797-805.

4. Chen JJ, Applebaum DS, Sun GS, Pflugfelder SC. Atopic keratoconjunctivitis: a review. J Am Acad Dermatol. 2014;70:569-75.

5. Garrity JA, Liesegang TJ. Ocular complications of atopic dermatitis. Can J Ophthalmol. 1984;19:21-4.

6. Uchio E, Miyakawa K, Ikezawa Z, Ohno S. Systemic and local immunological features of atopic dermatitis patients with ocular complications. $\mathrm{Br} \mathrm{J}$ Ophthalmol. 1998;82:82-7.

7. Govind K, Whang K, Khanna R, et al. Atopic dermatitis is associated with increased prevalence of multiple ocular comorbidities. J Allergy Clin Immunol. 2019;7:298-9.

8. Ohmachi N, Sasabe T, Kojima M, et al. Eye complications in atopic dermatitis. Areruga. 1994;43: 796-9 (article in Japanese).

9. Bielory B, Bielory L. Atopic dermatitis and keratoconjunctivitis. Immunol Allergy Clin $\mathrm{N}$ Am. 2010;30:323-36.

10. Sehgal VN, Jain S. Atopic dermatitis: ocular changes. Int J Dermatol. 1994;33:11-5.

11. Rich LF, Hanifin JM. Ocular complications of atopic dermatitis and other eczemas. Int Ophthalmol Clin. 1985;25:61-76.

12. Braude LS, Chandler JW. Atopic corneal disease. Int Ophthalmol Clin. 1984;24:145-56.

13. Akinlade B, Guttman-Yassky E, de Bruin-Weller M, et al. Conjunctivitis in dupilumab clinical trials. Br J Dermatol. 2019;181:459-73.

14. Blauvelt A, de Bruin-Weller M, Gooderham M, et al. Long-term management of moderate-to-severe atopic dermatitis with dupilumab and concomitant topical corticosteroids (LIBERTY AD CHRONOS): a 1-year, randomized, double-blinded, placebo-controlled phase 3 trial. Lancet. 2017;389:2287-303. 
15. Rosario N, Bielory L. Epidemiology of allergic conjunctivitis. Curr Opin Allergy Clin Imunol. 2011;11:471-6.

16. Bousquet J, Devillier P, Anto JM, et al. Daily allergic multimorbidity in rhinitis using mobile technology: a novel concept of the MASK study. Allergy. 2018;73:1622-31.

17. Thyssen JP, de Bruin-Weller M, Paller AS, et al. Conjunctivitis in atopic dermatitis patients with and without dupilumab therapy-international eczema council survey and opinion. J Eur Acad Dermatol Venereol. 2019;33:1224-311.

18. Thyssen JP, Heegaard S, Ivert L, et al. Management of ocular manifestations of atopic dermatitis: a consensus meeting using a modified Delphi process. Acta Derm Venereol. 2020;100:adv00264. 